\title{
Creating Competitive Advantage and Building Capital through Corporate Social Responsibility: An Exploratory Study of Hospitality Industry Practices
}

\author{
Sandra Sydnor ${ }^{1}$, Jonathon Day ${ }^{1} \&$ Howard Adler ${ }^{1, *}$ \\ ${ }^{1}$ School of Hospitality and Tourism Management, Purdue University, Marriott Hall, Indiana 47907, USA \\ *Corresponding author: School of Hospitality and Tourism Management, Purdue University, West Lafayette, Indiana \\ 47907, USA
}

Received: January 16, 2014

Accepted: February 8, $2014 \quad$ Online Published: February 17, 2014

doi:10.5430/mos.v1n1p52

URL: http://dx.doi.org/10.5430/mos.v1n1p52

\begin{abstract}
Hospitality industry managers respond to a wide variety of requests from stakeholders, both internal and external, and even the smallest hospitality company practices corporate social responsibility (CSR). The foundations of these actions can be traced to the interrelated concepts of social capital and stakeholder theory. The present exploratory study used qualitative methods to determine how managers understand and operationalize CSR, how managers determine appropriate stakeholders to support, and what benefits managers expect from CSR activities. Three focus groups were conducted, involving a total of 11 owner/ managers of hospitality firms from a medium-sized Midwestern town. The study found that managers considered CSR activities to be an important business strategy but tended to respond reactively to stakeholder requests. While managers did not typically have specific rubrics for analyzing CSR opportunities, they were inclined to prioritize based on the type of stakeholder involved and relevance to the local community. Finally, as observed, CSR activities are motivated by business and personal reasons.
\end{abstract}

Keywords: Corporate Social Responsibility, social capital, hospitality industry community work, corporate giving

\section{Introduction}

The roles of businesses in society and the expectations of the community towards corporations to contribute to social issues are dynamic and evolving. Corporate responses to social issues range from disregard to proactive advocacy. Within that continuum, companies may choose roles of legal compliance, responsiveness to social demands, or social responsibility in response to contemporary social issues (Robbins \& Coulter, 2012). Corporate response to social issues is not uniform and companies may respond to specific issues in different ways based on factors including (but not limited to) corporate culture, organizational norms, and stakeholder expectations.

\subsection{Corporate Social Responsibility}

The role of business in addressing social issues has been a topic of discussion for over one hundred years. Milton Friedman (1970) captured the perspective of the classical view (Robbins \& Coulter, 2012) when he declared that the 'social responsibility of business was to increase profits'. In recent years, a socio-economic view (Robbins \& Coulter, 2012) has become more common to describe business responses to social issues. This socio-economic view includes corporate responsiveness, in which corporations respond to social issues based on stakeholder pressure and corporate social responsibility. Conceptually, CSR can be understood as 'a business's intention, beyond its legal and economic obligations, to do the right things and act in ways that are good for society' (Robbins \& Coulter, 2012). The concept provides considerable scope for corporate response and has challenged both academics and practitioners to provide a more operational definition. Dahlsrud (2006) examined thirty seven definitions of CSR and determined there are 5 dimensions in defining CSR: environmental, social, economic, stakeholder, and voluntariness. These dimensions are evident in what Dahlsrud (2006) described as the most frequently cited definition of CSR: 'A concept whereby companies integrate social and environmental concerns in their business operations and their interaction with their stakeholders on a voluntary basis'. Within organizations, these dimensions often translate to programs that 
incorporate employee issues, diversity, environment, community support, and supplier relations (Albinger \& Freeman, 2000; Holme \& Watts, 2000; Murray \& Ayoun, 2011; Turban \& Greening, 1997).

Exisiting research reveals a variety of reasons for businesses to undertake corporate social responsibility. Lipshitz (2013) states that a company' market success may depend on how it shows its commitment to CSR and how genuine it is. He goes on to say that this can be done by engaging your employees, engaging with external stakeholders and finding unique ways to lead through a companies culture and skills. Porter and Kramer (2008) noted that CSR is often justified in terms of enlightened self-interest, moral appeal, license to operate, and rotation enhancement and propose that CSR can contribute to strategic competitive advantage. Similarly, Carroll and Shebana (2010) identified the competitive advantage created by CSR and proposed that the business case for CSR also incorporates cost and risk reduction, reputation and legitimacy, and synergistic value creation. One rich stream of research examines the impact of corporate responsible activities on the organization itself. Research has identified that CSR reduces turnover (Vitaliano, 2010), increases attractiveness of the employer (Albinger \& Freeman, 2000; Bhattacharya, Sen, \& Korschun, 2008; Turban \& Greening, 1997), and increases job satisfaction (Wang \& Hsieh, 2012). CSR policies are directed not only on how well a company complies with legal and ethical standards but how far beyond that they go in engaging the social or environmental or community good ( Lipshitz 2013).

\subsection{CSR in the Hospitality Industry}

The hospitality industry has embraced CSR and most major hospitality corporations report engaging in socially responsible activities. Holcomb, Upchurch, and Okumus (2007) noted that the top 10 hotel companies frequently report on community issues, the environment, the workforce, marketplace behavior, and their vision and values. Extant research has focused on several areas of CSR activity including green programs, internal employee programs such as diversity and workers' rights, and philanthropy (Bohdanowicz, 2007; Bohdanowicz \& Zientara, 2008; Council, 2002; Goldstein, Cialdini, \& Griskevicius, 2008; Kasim, 2006).

While major hospitality companies report CSR as an aggregate, one must note that much of the activity takes place within specific communities. Many hospitality companies are locally-owned small- or medium-sized enterprises; even hospitality operations with larger brands are characterized by decentralized operations and management. While recent studies in the hospitality industry have examined the motivations of independent hotel managers (Njite, Hancer, \& Slevitch, 2001) there has been no study of the broader hospitality and tourism sector. The reach of the hospitality industry into communities across America is noteworthy: there are over 52,000 hotels (STR, 2012) and 970,000 restaurant locations (NRA, 2012) in the United States. In each of these locations, management holds some level of discretion over local responses to social issues. One result of this decentralization is that CSR activities are dispersed widely throughout the community and, while specific contributions tend to be relatively small, cumulative contributions are substantial. McGehee et al. (2009), after surveying 421 hotels, noted that community contributions by the lodging industry in 2005 could be estimated at 3.6\% of industry profits and over \$815 million.

Almost every hotel company has policies stated on their web pages. One example of this is Choice Hotels which has a "Room for Responsibility" framework which includes room to be green, room to rebuilt, room to give and room for everyone. Each of these encompasses a different area of potential social responsibility which is franchises can become involved in (Choice Hotel 2014).

\subsection{Theoretical Foundation of CSR}

Stakeholder theory and theories of Social Capital (SC) are considered salient to the examination of socially responsible actions by small business owners and managers in the hospitality industry. In the broadest sense, stakeholders are defined by Freeman as 'any group or individual who can affect or is affected by the achievement of the organizations objectives'. Considerable research has been undertaken to determine what criteria should be used to assess relationships between stakeholders and organizations. Identifying who the organizations' stakeholders are and who are most important to the manager are two key questions identified in extant research (A. Friedman \& Miles, 2002; Mitchell, Agle, \& Wood, 1997) and pose practical challenges to managers of small and large enterprises. Common stakeholder types include governments, investors, political groups, customers, communities, employees, trade associations, and suppliers (Donaldson \& Preston, 1995). However, the manner in which the enterprise responds to the demands of each group is based on a variety of factors (Donaldson \& Preston, 1995; Mitchell et al., 1997). The moral dimension of the obligations of organizations to various stakeholders and normative concerns (Donaldson \& Preston, 1995) is the foundation to the examination of stakeholder theory. Research concerning the roles of stakeholders and research into the growing expectations of business to be socially responsible have been mutually supportive. For this reason, CSR is often discussed in terms of stakeholder theory. 
Stakeholder theory is both descriptive and instrumental. As such, one finds it useful to identify 'the connections' between the stakeholder and the enterprise (Donaldson \& Preston, 1995). Indeed, building relationships with stakeholders is an important outcome of CSR (Carroll \& Shabana, 2010). Such concern with the relationship and connections between stakeholders and the enterprise can be illuminated further by theories of social capital. Putnam (2004, p. 14) described social capital as ' ....social networks and the associated norms of reciprocity'. Development of social capital has been shown to have a number of positive outcomes for organizations, including increased productivity (Brien, Ratna, \& Boddington, 2012), intellectual capital development (Manning, 2009), and increased resilience (Sydnor-Bousso, Stafford, Tews, \& Adler, 2011). CSR activities, from concern for employee issues, diversity, the environment, and community support to supplier relations build social capital for both organizations and individual managers within those businesses. The firms studied here simultaneously represent independent and chain-owned, locally operated business; they are all small businesses (revenues less than \$30,000,000 for hotels and $\$ 10,000,000$ for restaurants as defined by the Small Business Administration; (USSBA, 2012). Accordingly, the present researchers acknowledge Njite et al. (2001) but engage social capital as an intrinsic antecedent of CSR. Lynn (2011) discuss the issues of altruistic CSR which involves a firm helping to alleviate external social problems and inequities through charitable functions whether it benefits or not. Strategic CSR involves choosing those activities which will somehow have benefits to the company while still helping people. Lastly ethical CSR involves those things which the company must do in order to obey the law and avoid doing harm to the planet or people etc.

\subsection{Purpose of the Research and Research Questions}

The purpose of the research was to examine typical CSR practices among owners and managers of smaller hospitality businesses in a medium size Midwestern city in the United States. Analysis of the existing literature raises a number of important questions that require further analysis. The current study addresses the following research objectives:

- How do managers define and operationalize social capital.

- Determine the extent and importance of socially responsible activities to hospitality business managers and the processes by which managers assess stakeholder salience when considering support for CSR support.

- Understand the motivation and expected benefits of CSR activities undertaken by businesses within local communities.

\section{Methodology}

The present research study employed a qualitative methodology using focus groups due to the exploratory nature of the inquiry. Focus groups ideally are suited as an exploratory research tool due to their efficacy of discovering new information, generating novel insights, and determining how group members reach decisions (Salkind, 2009). Babbie (2011) suggested the need for capturing 'real life' information is served well by focus groups' socially-oriented research methodology. The focus groups' assumptions and worldviews compliment the study of research problems that delve into the meaning individuals or groups ascribe to a social or human circumstance or problem. The data analytic process is inductive, noting patterns and themes of the participants. The final report includes the voices of participants, the reflexivity of the researcher, and a complex description and interpretation of the problem (Creswell, 2009).

\subsection{Participants}

Based on the research objectives of the present study, a purposive, nonrandom sample included owners and managers of hospitality and tourism businesses in a medium-sized Midwestern city. Patton (1990) recommends purposeful sampling for in-depth information-rich contexts about which one expects to learn a great deal about issues of central importance to the purpose of the research (p. 169). Individuals invited to participate were intended to be representative of a cross-section of hospitality businesses in the area. A list of the names of prospective participants was developed through the contacts of faculty in the area of hospitality and tourism at a research university. Individuals were contacted and the purpose of the research explained. Potential respondents who agreed to participate were then given a time and place for the focus group. Specifically, participants were assured of confidentiality and that their comments would be coded. Focus groups would be kept to no more than 6 participants. There were 3 different focus groups which allowed for a more intimate exchange of ideas concerning the research topic and achieved a theoretical saturation point: the data collection point beyond which any new conceptual insights are generated (Bloor \& Wood, 2006). Each focus group had a mixture of participants from various segments of the hospitality industry including the following: 


\section{Focus Group 1}
A. General manager overseeing 2 major franchise hotels
B. Owner of a chain of restaurants in the local area
C. Manager of a fine dining restaurant
D. Owner of a fine dining restaurant
E. Executive director of a local Convention and Visitors' Bureau

\section{Focus Group 2}
A. General manager overseeing 2 major franchise hotels
B. Owner/manager of a large travel agency
C. Manager of a fast food ethnic restaurant franchise
D. General Manager of a fast food ethnic restaurant franchise

\section{Focus Group 3}
A. Owner/manager of a local pub restaurant

B. Owner/manager of a travel agency and limousine service

\subsection{Setting and Procedures for the Focus Groups}

The 3 focus groups met at a university in a Midwestern city where participants operated their businesses. Individuals were invited for an early morning breakfast at a restaurant on the university campus where the authors were employed to allow for a more relaxed atmosphere and to take into account their busy schedules. Participants were asked their permission for all sessions to be recorded. The moderator for the focus group was a professor with extensive industry experience in operating hospitality businesses. In addition, 2 other research team-members listened to the discussions and added input when necessary. Approximately 2 hours were allocated for the completion of each of the focus groups.

To ensure that the focus groups generated a wide spectrum of insights about CSR in the community, the moderator clearly established a forum for open discussion concerning the topics. The moderator greeted participants and introduced them to other participants and observers. The moderator then explained the objectives of the focus group and how the focus group would be conducted. The moderator explained that her role was to move the conversation forward and to insure that the various subjects were discussed and that all participants had opportunities for involvement. Participants were informed about the following information to guide their responses: (1) that there is no right or wrong answer; (2) that this is exploratory research and the researchers are looking for general guidelines; and (3) that participants should be candid with their responses in that the discussion is anonymous and confidential. Participants were encouraged to volunteer related information useful to the conversation.

Based on a thorough review of the literature, the moderator prepared a semi-structured discussion guide. The goal was to ask a leading question and then have the participants volunteer opinions, attitudes, and perceptions relative to the topic. Then the moderator of the focus group would paraphrase what each person said to insure that the meaning was understood. The 3 major themes to achieve the objectives for the focus group concerned (1) identifying types and descriptions of managerial behaviors associated with organizational social capital and corporate social responsibility; (2) developing an understanding of the 'if and why' (motivations) for managerial participation in community activities; and (3) determining the salience of recognition, rewards, or payoffs for these behaviors, both intangible and measurable.

\subsection{Data Analysis}

After completion of all 3 focus groups, recordings were downloaded and transcribed to give the researcher an opportunity to detect emergent themes from the data consistent with the categories previously mentioned. Subsequently, content analysis was conducted with the aid of a qualitative software package, QSR International's NVivo 9 software. The current study adopted a research methodology using qualitative data analysis using QSR International's NVivo 9 software established by Welsh (Welsh, 2002). Results of the content analysis were shared with faculty and research team members involved to check for inter-rater reliability (consistency) and clarification of any confusing dialogue. Widespread agreement and no confusion were noted before, during, or after content analyses. 


\section{Results and Discussion}

Corporate Social Responsibility (CSR) was defined by respondents in terms of support for stakeholders, particularly staff and valued customers, and for local community causes. For most participants CSR involved, almost exclusively, proactive and reactive behavioral involvement in community activities in support of local causes (organizations) and people (customers, employees). The most common mention was participation in events, donating time, making product and staff available for community fund-raisers and national charities (such as the American Heart Association, the Red Cross, and the March of Dimes), and sheltering people or giving to food banks. Respondents were universally sensitive to the large number of requests they confront daily and distinguished between these and personal appeals of staff members encountering difficult temporary circumstances (such as family illness).

Deciding how to respond to requests is the province of the owner or the general manager and most participants followed implicitly derived decision rules. Within-industry support seemed to provoke favor and several participants recalled circumstances that led to co-opetition (combining the advantages of both competition and cooperation), particularly with routine acts such as sharing inventory with a competitor during depleted food inventories of a critical period. While inherently established relationships appeared to involve minimal cognitive elaboration for most participants ('One is the personal relationships and usually we have a customer like [sic] and then there's just those other organization where your heart's there'), such a feeling was not universal ('My rule, nothing personal. However, unless it's one of my employees.'). Almost universally, employee assistance dominated exceptions to the implicitly derived decision rules. Participants in the hospitality and tourism industry in this Midwestern region had similar comments about how they relaxed their decision-making conventions regarding employees in need. They provided reasons such as ill children, personal illness, and financial hardship as motivations to assist employees of their organizations and others and likened them to internal social capital.

Hotelier 2 'So our giving is directly related to the community. If I get something from (or) about a gentleman that has cancer and there's a benefit, unfortunately, I can't fulfill that...'

Restaurateur 3 'Ok. So I'll say, one of our interests is breast cancer awareness and women's things. That got started at an early age, you know, my father employed a lot of women. And so women's issues were always number one on his list...'

Hotelier1 'And I think to if there's a team member in trouble, I know, [sic] one of our bartender's child was desperately ill so we did a fundraiser. So I think if it's..... you've got a team member that might be in trouble financially or something ...so I think it becomes more personal I guess and when its personal you tend to be more engaged with personnel.'

Participants agreed that for local-owned chain businesses, deciding where to draw the line concerning requests for aid (reactive CSR) can be somewhat ambiguous.

Restaurateur 3 'So fine line there. My rule, nothing personal. However, unless it's one of my employees.'

\subsection{Local (Organizational) Social Capital}

The concept of social capital is of interest to multiple disciplines and researchers primarily due to its perpetual inclusion as a robust explanatory construct. Social capital's reported influence has been used to describe positive effects on community disaster resilience, health outcomes, voting participation, reduction of crime, and community economic development (Adger, 2003; Cutter, Burton, \& Emrich, 2010; Norris, Stevens, Pfefferbaum, Wyche, \& Pfefferbaum, 2008; Sherrieb, Norris, \& Galea, 2010; Sydnor-Bousso et al., 2011; Woolcock, 1998). Moreover, micro-level impacts of social capital on community economic performance, market outcomes, and entrepreneurial ventures have been demonstrated as significant outcome predictors (Dahl \& Sorenson, 2012; Kurt, 2003).

Social capital's influences also can be examined through the built environment, geography, or a locality. Because the lens is a specific community, the researchers focused on local social capital. Geography, or place-based social capital is built and sustained (or not) via shared networks, values, and norms and has the capacity to perform a critical role in local businesses and the communities where they reside. These norms and values create reciprocal adherence and peer pressure that may encourage businesses to invest in social capital behaviors and activities that benefit both businesses and the community. Evidence of a positive relationship between corporate social responsibility and hotel firm performance provides support for the influence of these relationships at a macro-level (Lee \& Park, 2009). At the micro level, local social capital and increased likelihood of survival of immigrant entrepreneurs' hotels affirm the basic premise (Kalnins \& Chung, 2006). Local social capital in particular may acts as a shield that decreases risk and enhances adaptation (Norris et al., 2008) so that 'the more people connect with each other, the more they will trust each other and the better off they will be individually and collectively...'(Mathbor, 2007, pp. 360-361). Thus, one 
turns attention to a geographically defined area and the impact of local social capital behaviors of the hospitality industry on competitive advantages that may ensue. Customers of these hospitality businesses, particularly repeat customers with whom these businesses have an established rapport, present an opportunity to care for the community and simultaneously generate goodwill for the business.

Restaurateur 3 'So when we look at things...there's two sides of looking at pretty much any donation. One is the personal relationships and usually we have a customer like [sic ...you don't really mess with them... there's a lot of weight, a lot of power. You want their recommendations. You want their business. And then there's the other, so there's the customer relationships and then there's just those other organization where your heart is there. For example there may not be an attachment for one restaurant to do something but that's in my backyard and it has been for ...50 years it's been around. It has a huge attachment to us because that's our neighborhood community center. So you're more apt to say oh, absolutely I'll do something for them. Where a lot of other relationships maybe don't have that business relationship?'

\subsection{Motivation for Participation}

Participants noted several stimuli for involvement in the community and in the industry's participation in the community. Substantial differences were observed between national chain companies and companies with founders of local chain companies and smaller independent unit owners/operators and their motivations for practicing corporate social responsibility. Support for locally-driven acts of benevolence were support directed by owner discretion (personal relationships, values), community needs (i.e. women's shelters), and the hospitality and tourism industry-associated beliefs and community expectations (subjective norms). Chain businesses with corporate influence and mandates target national organizations with planned and budgeted support (i.e. March of Dimes, American Cancer Society).

Restaurateur 3 'Locals have a different angle of competition. They have to compete differently. And chains have national advertising. Everybody knows where Outback is. Everybody knows where Applebee's is. Because they're on the TV and the radio all the time. Right?

Restaurateur 3 'Domino's, Pizza Hut, all of those, they're so well advertised that people know where they are. People need to know where are. So we have to compete differently and what we do is we compete one for one'.

Participants spoke of corporate social responsibility as part of who they are and what they do.

Restaurateur 3 'Our customers are our community, I mean, our community is our customer base. So we're either gonna take care of all of the customers that we feel are part of our community or vice versa. You gotta take care of the community to continue building your customer base. I think that part of that may be profit and loss driven but another part of it is that it's just engrained into what we do every day. I mean, that's what we do, we take care of our community.'

There were distinct differences between manufacturing and locally-owned hospitality businesses' motivations for engaging the community.

Restaurateur 3 'That's the old [sic] manufacturing plant. So they [sic] have a plant out here that employs, I don't know, 700 people now.... They're not as engaged on the individual customer community level that we are. So we sort of have a different... way of looking at taking care of the community.'

\subsection{Benefits of Corporate Social Responsibility (recognition, rewards and payoffs for behavior)}

Respondents noted that the rationale for undertaking CSR incorporated a variety of expected benefits. They were motivated by both intrinsic and extrinsic factors.

Restaurateur 3 'The one point I wanted to say though was I don't know any better. So when you talk about competing locally, this is what I know how to do in our community. Ok. Either it's how I was raised or it's just how I know to compete in this town. So for me to put Arni's on the table, I have to do these, in my mind, I have to participate. And I love doing it, it's not like I have to because it's my job. I do it because I live here, I shop here, I eat here...I want to make this community a better place so I'm going to walk, if I'm gonna walk the walk, talk the talk, if I want this place to be a better place then I sure as hell better work on making it a better place so that's how I compete and it's not just compete, that's how I participate.'

CVB 1 'The other tangible benefit too though, in being there for people, is people are there for you too. I do think that they get more customers. We know that when we're in trouble, the people that we've worked with or 
whatever, are there for us. If it's to talk to a legislator, if it's to back off from a half-marathon promoter that's no good or if its, you know, if it's a difficult situation, you know if you've worked with them or you've volunteered or you've been out in the community and you know these people it's so much easier to call up and say, 'I'm in trouble, can you help?' And that's a real tangible benefit that you can't put a monetary value on it, sometimes you can with your budget cuts or whatever, but it is very tangible. They're out there and it does tend to be the local folks...'

Hotelier 1 'Well you know, what stinks about us, is we don't look for it and... I don't think we look for it because we're already on the next thing going... Where a bigger corporation or a manufacturing will get it because they impact immediately to the community and because they employ a thousand people and you know they're a bigger gun than (company name). But I just don't think we look for that recognition. And they've got a staff person that can call up and yell because their logo wasn't printed right in such and such a publication to promote them ...'

Most participants agreed that while their individual activities are ostensibly small, in the local industry aggregate, the sum of the parts is bigger than the whole. Similarly, while multiple-unit chains and corporate franchisors are commonly associated with primary gifting and funding efforts, it is the local business owner who has an enduring presence and, hence, community impact.

Restaurateur 3 'The big chains move people. You gotta move out to move up...The old corporate thing....it's hard to get people to stick around and participate in their community and the bottom line is the best places that participate are the ones that are here for a while...'

\section{Conclusions and Implications}

The current study addressed 3 key research issues critical to understanding how hospitality companies in local communities implement CSR-related activities. The study sought to determine how hospitality managers define and operationalize CSR, to determine the processes by which managers assess stakeholder salience when considering support for CSR support, and to understand the motivation and expected benefits of CSR activities undertaken by businesses within local communities.

All the companies reported undertaking activities that meet recognized definitions of CSR. These activities ranged from providing support to employees to supporting national charities. Companies responded in a variety of ways to perceived social needs. Managers reported committing organization resources - financial, labor, and/or products and services - to various social issues. These included direct financial donations to causes, commitment of staff time to community projects or the offer of company products and services, such as hotel rooms or meals, for charitable fund-raising purposes. While each of these activities results in increased costs for the company, some managers reported ways to mitigate the cost of their support of social issues by offering products at rates sufficient to cover costs. Some managers used this approach as a means of generating marginal sales. In other circumstances, companies 'co-opt' with employees in socially responsible activities. This can be employee-driven, such as allowing staff paid time for community support, or company-driven in which the company encourages employees to participate in charitable activities without compensation. While the latter technique raises issues of power and influence, respondent managers perceive that these types of activities often build camaraderie and social capital within organizations. Managers also use their social capital within the community to support social causes without direct cost to their companies. Examples of such action include promoting charitable events in public places in their business or in staff newsletters.

The managers surveyed consider decisions regarding CSR to be important and often retain control of these decisions. In determining which social issues to address, managers rely on personal assessments of the perceived value of the activity. This is particularly evident in locally-owned businesses which have no explicit rubric for decision-making and prioritizing in regards to contributing to the community. While none of the managers reported a specific rubric for CSR, decisions were guided by several factors including relevance to the company, cost to the company, and nature of the stakeholders. Projects that were relevant to the company and involved market based stakeholders, such as a staff member with a chronically sick child, were more likely to receive consideration. One also may note that while managers recognize the importance of CSR related activities and even budget for these activities, they demonstrate a reactive behavioral involvement in community activities that support local causes (organizations) and people, particularly employees and customers.

The study revealed that managers believe their CSR activities have a variety of benefits including human 
resource-related benefits, such as increased team cohesion and lower turnover, as well as increased goodwill in the community. Businesses benefit from their participation by affirming industry and community expectations; quid-pro-quo ('in being there for people... [sic] people are there for you too..'). While managers expected a positive return from their CSR activities over the long term they did not necessarily expect direct benefits from each activity. It was expected that the cumulative benefits of activities over a period of time would lead to a positive return for the company and the individual manager. Such a finding suggests that there is a need for practical metrics, based on short and long-term goals, for small businesses in hospitality. These metrics would allow managers to track results and improve business effectiveness and efficiency.

While managers do not expect a direct benefit from each activity, they do seek to establish a reputation as supportive of the community and expect to receive goodwill from those commitments. In this respect, hospitality managers report frustration at the level of recognition they receive. Tourism has been described as the 'invisible industry' and it appears that tourism and hospitality related CSR is also largely invisible. While hospitality industry contribution to communities is large in aggregate (McGehee et al., 2009), each contribution tends to be relativity small, given by many small organizations and dispersed to many charities and social causes throughout the year. This is in contrast to contributions by locally-based manufacturers that are perceived by hospitality managers as a single large check to a local charity once a year and receive media attention. This frustration does not eliminate managerial perceptions that they can do well (generate goodwill for the business) and do good (care for the community); it does highlights the need for these organizations to communicate their actions effectively, particularly to important stakeholders, such as staff, key customers, and the local community. Promoting CSR activities in a way that does not appear self-serving and cause stakeholders to question the sincerity and genuine concern of the organizations' managers is an important skill. The present findings suggest that there is a need for managers from small businesses to develop skills in the promotion of CSR activities in ways that spread the word about the positive actions they take to receive the benefits from their actions.

Moreover, managers are not only motivated by businesses objectives but also personal values and objectives. Business people are inspired to participate because 'that's the way I was raised-I don't know any differently' and via personal relationships, personal and corporate values, community needs, industry beliefs, and community expectations (subjective norms). The present research revealed that each manager works through these choices individually, often using intuitive judgments and tacit knowledge. Given these challenges, small business managers in the hospitality industry would benefit from being able to share their experiences with industry counterparts in dealing with CSR issues.

While managers sought benefits for their companies from CSR activities, there is an important personal component to these activities. Managers frequently reserved decision-making concerning CSR activities for themselves, ensuring that social capital for decisions of support accrued to both themselves and their organizations. Managers, particularly managers committed to the community, were likely to consider CSR differently from managers who were transitory. Hence, managers from family companies, local entrepreneurs or managers working for large chains that expected to be part of the community for the long-term were more highly motivated to undertake CSR initiatives. This is to be expected as the perceived lifetime value of the community-based social capital these locally based managers accrue is greater than for managers who expect to leave the community within a year or two. One implication from this finding is that larger organizations that wish to create competitive advantage in communities through CSR must find other incentives to encourage their transitory managers to engage with the community.

The present study provided useful insight into CSR activities undertaken by hospitality organizations. These activities can be characterized as basically small, dispersed, often locally oriented activities. The nature of the tourism and hospitality industry, in which there are many relatively small businesses making decisions in an uncoordinated manner, means that the benefits of hospitality CSR, particularly hospitality philanthropy, permeates the entire community in small ways. The disadvantage of such an approach is that it is uncoordinated and may not address the greatest community needs.

The study also provided a snapshot for understanding applications of stakeholder theory to the hospitality industry. Notably, managers undertake CSR activities with a favorable bias toward 'market stakeholders', particularly staff and customer, identified social issues. Managers support national social causes, such as charities, when there is a local connection. The present study also provided a useful link between CSR and social capital. Managers use corporate social responsibility as a means of 'bonding' and 'bridging'. These activities can increase social capital directly; the company's support of a customer's charity strengthens the bonds between the company and the customer. 
It has been established that hospitality industry is a significant generator of economic activity. In 2010 (NAICS code 72), hotels and restaurants represented almost ten percent (644,000 establishments) of all US establishments, contributed \$185,590,987,000 in annual receipts ("U.S. Census Bureau American Factfinder: County Business Patterns," 2010) and employed over eleven million $(11,312,122)$ people during the first quarter of March 2010. This research highlights the hospitality industry's significant contribution to the social well being of host communities. These social contributions have gone largely unnoticed, even by the members of the hospitality industry itself, as many of the actions are local and relatively small, even though the aggregate benefit is substantial (McGehee et al., 2009). Of particular note is that these socially responsible investments are made, for the most part, by non-routine owner and management discretion.

11 million people are employed directly or indirectly in the hospitality industry and are located in every community across the United States. These people are often unsuspecting of the influence the hospitality industry wields on community and wellbeing investments, and perhaps, of the capacity for an even greater system impact. Perhaps the greatest contribution this research adds to our existing knowledge is highlighting opportunities for industry managers to collaborate and maximize collective investments for community development and benefit. Intentionally harnessing the means of a pool of eleven million human resources could, conceivably transform life for thousands.

\section{Limitations and Future Research}

The present study provided useful insights into the importance of Corporate Social Responsibility in local communities and a new perspective on the applications of stakeholder theory and social capital development. Nevertheless, the current study has some limitations: the findings are exploratory and based on focus group discussions with 11 managers all from the same city in the Midwest of the United States.

The contribution of CSR to local communities is an important topic that requires more research. The hospitality and tourism industry contributes significantly to the well-being of communities across the United States, but there has been little examination of this process. Insights from the United States may be applicable to other countries and contribute to understanding how tourism can be used as a mechanism for both positive economic and social impact.

\section{References}

Adger, W. (2003). Social Capital, Collective Action, and Adaption to Climate Change. Economic Geography, 79(4), 387-404. http://dx.doi.org/10.1111/j.1944-8287.2003.tb00220.x

Albinger, H., \& Freeman, S. (2000). Corporate Social Performance and Attractiveness as an Employer to Different Job Seeking Populations. Journal of Business Ethics, 28(3), 243-253. http://dx.doi.org/10.1023/A:1006289817941

Babbie, E. (2011). The Basics of Social Research. Belmont, Ca: Wedsworth.

Bhattacharya, C., Sen, S., \& Korschun, D. (2008). Using Corporate Social Responsibility to Win the War for Talent. MIT Sloan Management Review(Winter), 37-44.

Bloor, M., \& Wood, F. (2006). Keywords in Qualitative Methods. Thousand Oaks, Ca: Sage.

Bohdanowicz, P. (2007). A Case Study of Hilton Environmental Reporting as a Tool of Corporate Social Responsibility. Tourism Review International, 11(2), 115-131. http://dx.doi.org/10.3727/154427207783948937

Bohdanowicz, P., \& Zientara, P. (2008). Hotel Companies' Contribution to Improving the Quality of Life of Local Communities and the Well-being of Their Employees. Tourism and Hospitality Research, 9(2), 147-158. http://dx.doi.org/10.1057/thr.2008.46

Brien, A., Ratna, N., \& Boddington, L. (2012). Is Organizational Social Capital Crucial for Productivity Growth? An Exploration of "Trust" within Luxury Hotels in New Zealand. Journal of Human Resources in Hospitality and Tourism, 11(2), 123-145. http://dx.doi.org/10.1080/15332845.2011.648840

Carroll, A., \& Shabana, K. (2010). The Business Case for Corporate Social Responsibility: A review of Concepts, Research and Practice. International Journal of Management Reviews, 12(1), 85-105. http://dx.doi.org/10.1111/j.1468-2370.2009.00275.x

Chiang, Chia-Chun. (2010). How corporate social responsibility influences employee job satisfaction. University of Nevada, Las Vegas, UNLV Thesis, disserations and professional papers, 2010. 
Choice Hotels. (2014). Corporate Web Site, Room for Responsibility. Retrieved from www.choicehotels.com

Cohen D., \& Prusak L. (2001). In Good Company, How Social Capital Makes Organizations Work. Harvard Business School Press: Boston Mass.

Council, W. T. T. (2002). Corporate Social Leadership in Travel \& Tourism.

Creswell, J. W. (2009). Research Design: Qualititive; Quantitative and Mixed Methods Approaches (Third ed.). Los Angeles: Sage.

Cutter, S., Burton, C., \& Emrich, C. (2010). Disaster Resillience Indicators for Benchlining Baseline Conditions. Journal of Homeland Security and Emergency Management, 7(1), 1-22. http://dx.doi.org/10.2202/1547-7355.1732

Dahl, M., \& Sorenson, O. (2012). Home Sweet Home: Entrepreneurs Location Choices and the Performance of their Ventures. Management Science, 58(6), 1059-1071. http://dx.doi.org/10.1287/mnsc.1110.1476

Dahlsrud, A. (2006). How Corporate Social Responsibility is Defined: An Analysis of 37 Definitions. Corporate Social Responsibility and Environmental Management. http://dx.doi.org/10.1002/csr.132

Donaldson, T., \& Preston, L. (1995). The Stakeholder Theory of the Corporation: Concepts, Evidence, and Implications. Academy of Management Review, 20(1), 65-91.

Friedman, A., \& Miles, S. (2002). Developing Stakeholder Theory. Journal of Management Studies, 39(1), 1-21. http://dx.doi.org/10.1111/1467-6486.00280

Friedman, M. (1970, Sept 13, 1970). A Friedman Doctrine - The Social Responsibility of Business is to Increase its Profits. New York Times.

Goldstein, N., Cialdini, R., \& Griskevicius, V. (2008). A Room with a Viewpoint: Using Social Norms to Motivate Environmental Conservation in Hotels. Journal of Consumer Research, 35 (Aug 2008).

Holcomb, J., Upchurch, R., \& Okumus, F. (2007). Corporate Social Responsibility: What are the top hotel companies reporting? International Journal of Contemporary Hospitality Management, 19(6), 461-475. http://dx.doi.org/10.1108/09596110710775129

Holme, R., \& Watts, P. (2000). Corporate Social Responsibility: Making Good Business Sense. World Business Council for Sustainable Development. Geneva: World Business Council for Sustainable Development.

Kalnins, A., \& Chung, W. (2006). Social Capital, Geography, and Survival: Gujarati immigrant entrepreneurs in the U.S. Lodging Industry. Management Science, 52(2), 233-247. http://dx.doi.org/10.1287/mnsc.1050.0481

Kasim, A. (2006). The Need for Business Environmental and Social Responsibility in the Tourism Industry. International Journal of Hospitality and Tourism Administration, 7(1), 1-22. http://dx.doi.org/10.1300/J149v07n01_01

Kurt, A. (2003). Social Capital, Social Inclusion and Economic Performance. Journal of Economic behavior and Organization, 50(4), 449-463. http://dx.doi.org/10.1016/S0167-2681(02)00035-5

Lee, S., \& Park, S. (2009). Do Socially Responsible Activities help Hotels and Casinos achieve their Financial Goals? International Journal of Hospitality Management, 28, 105-112. http://dx.doi.org/10.1016/j.ijhm.2008.06.003

Lipshitz, Ian. (2013). It's Time to Start Thinking about Corporate Social Resonsibility. Huffington Post, August 8, 2013.

Lynn, C. (2009). Corporate Social Responsibility in the Hospitality Business. Hosteur Magazine, October 2009.

Manning, P. (2009). Explaining and Developing Social capital for Knowledge Management Purposes. Journal of Knowledge Management, 14(1), 83-99. http://dx.doi.org/10.1108/13673271011015589

Mathbor, G. (2007). Enhancement of Community Preparedness for Natural Disasters. International Social Work, 50(3), 357-369. http://dx.doi.org/10.1177/0020872807076049

McGehee, N., Wattanakamolchai, S., Perdue, R., \& Calvert, E. (2009). Corporate Social Responsibility within the U.S. Lodging Industry: An Exploratory Study. Journal of Hospitality and Tourism Research, 33(3), 417-437. http://dx.doi.org/10.1177/1096348009338532

Mitchell, R., Agle, B., \& Wood, D. (1997). Towards a Theory of Stakeholder Identification and Salience: Defining the principle of Who and What Really Counts. Academy of Management Review, 22(4), 853-886. 
Murray, D., \& Ayoun, B. (2011). Hospitality Student Perceptions on the Use of Sustainable Business Practices as a Means of Signalling Attractiveness and Attracting Future Employees. Journal of Human Resources in Hospitality and Tourism, 10, 60-79. http://dx.doi.org/10.1080/15332845.2010.500211

Njite, D., Hancer, M., \& Slevitch, l. (2001). Exploring Corporate Social Responsibility: A Managers' Perspective on How and Why Small Independent Hotels Engage with Their Communities. Journal of Quality Assurance in Hospitality and Tourism, 12(3), 177-201. http://dx.doi.org/10.1080/1528008X.2011.541833

Norris, F., Stevens, S., Pfefferbaum, B., Wyche, K., \& Pfefferbaum, R. (2008). Community Resilience as a Metaphor, Theory, Set of Capacities and Strategy for Disaster Readiness. American Journal of Community Pyschology, 41, 127-150. http://dx.doi.org/10.1007/s10464-007-9156-6

NRA. (2012). Facts at a Glance. Retrieved 10/8/2012, 2012, from www.restaurant.org/research/facts/

Patton, M. (1990). Qualitative Evaluation and Research Methods. Beverly Hills, Ca: Sage.

Porter, M., \& Kramer, M. (2008). Strategy and Society: The Link between Competitive Advantage and Corporate Social Responsibility. In M. Porter (Ed.), On Competition: Updated and Expanded Edition (pp. 451-479). Boston, MA: Harvard Business Review Books.

Putnam, R. (2004). Bowling Together. The OECD Observer. Organization for Economic Cooperation and Development(Mar 2004), 14-15.

Robbins, S., \& Coulter, M. (2012). Management (11th ed.). New Jersey Prentice Hall - Pearson.

Salkind, N. (2009). Exploring Research. Upper Saddle River, NJ: Pearson Education.

Sherrieb, K., Norris, F., \& Galea, S. (2010). Measuring Capacities for Community Resilience. Social Indicators Research, 99(2), 227-247. http://dx.doi.org/10.1007/s11205-010-9576-9

STR. (2012). 2012 Lodging Survey: Lodging Services, Facilities and Trends. Washington DC: American Hotela nd Lodging Association.

Sydnor-Bousso, S., Stafford, K., Tews, M., \& Adler, H. (2011). Towards a Resilience Model for the Hospitality and Tourism Industry. Journal of Human Resources in Hospitality and Tourism, 10(2), 195-217. http://dx.doi.org/10.1080/15332845.2011.536942

Turban, D., \& Greening, D. (1997). Corporate Social Performance and Organizational Attractiveness to Prospective Employees. Academy of Management Journal, 40(3), 658-672. http://dx.doi.org/10.2307/257057

U.S. Census Bureau American Factfinder: County Business Patterns. (2010). Retrieved from http://factfinder2.census.gov/faces/tableservices/jsf/pages/productview.xhtml?pid=BP_2010_00A1

USSBA. (2012). Table of Small Business Sized Standards Matched to North American Industrial Classification System Codes $\quad$ Retrieved 11/5/2012, $\quad 2012, \quad$ from http://www.sba.gov/sites/default/files/files/Size_Standards_Table(1).pdf

Vitaliano, D. (2010). Corporate Social Responsibility and Labor Turnover. Corporate Governance, 10(5), 563-573. http://dx.doi.org/10.1108/14720701011085544

Wang, Y., \& Hsieh, H. (2012). Toward a Better Understanding of the Link Between Ethical Climate and job satisfaction: A Multilevel Analysis. Journal of Business Ethics, 105, 535-545. http://dx.doi.org/10.1007/s10551-011-0984-9

Welsh, E. (2002). Dealing with Data: Using NVivo in the Qualitative Data Analysis. Forum Qualitative Sozialforschung / Forum Qualitative Social Research, 3(2), 26.

Woolcock, M. (1998). Social Capital and Economic Development: Toward a Theoretical Synthesis and Policy Framework. Theory and Society, 27(2), 151-208. http://dx.doi.org/10.1023/A:1006884930135 